Article

\title{
The Effect of Transport Accessibility on the Social Inclusion of Wheelchair Users: A Mixed Method Analysis
}

\author{
Raquel Velho ${ }^{1, *}$, Catherine Holloway ${ }^{2}$, Andrew Symonds ${ }^{3}$ and Brian Balmer ${ }^{1}$ \\ ${ }^{1}$ Department of Science and Technology Studies, University College London, Gower Street, London, WC1E 6BT, UK; \\ E-Mails: raquel.velho.12@ucl.ac.uk (R.V.), brian.balmer@ucl.ac.uk (B.B.) \\ ${ }^{2}$ Department of Computer Science, University College London, Gower Street, London, WC1E 6BT, UK; \\ E-Mail: c.holloway@ucl.ac.uk \\ ${ }^{3}$ Institute of Orthopaedic and Musculoskeletal Sciences, University College London, Stanmore, HA7 4LP, UK; \\ E-Mail: andrew.symonds.12@ucl.ac.uk \\ * Corresponding author
}

Submitted: 20 October 2015 | Accepted: 9 February 2016 | Published: 7 June 2016

\begin{abstract}
In recent years the accessibility of London buses has improved with the introduction of ramps and wheelchair priority areas. These advances are meant to remove physical barriers to entering the bus, but new conflicts have arisen particularly over the physical space aboard. We aimed to research the barriers faced by wheelchair users in public transport using a mixed methods approach to establish the breadth of issues faced by wheelchair users. To this end we quantified the push-force used alight a bus and a study to understand the coping mechanisms used by people to propel up a ramp. This quantitative approach found push forces which resulted in a load of 2 to 3 times body weight being transferred through people's shoulders, forces which can be directly linked to shoulder injury. This could disable the user further, preventing them from being able to push their wheelchair. Alongside the quantitative study, we conducted qualitative research comprising of a number of in-depth interviews with wheelchair users about the barriers they face in public transport. Our main claim, highlighted through this interdisciplinary collaboration, is that proposed 'solutions' to accessibility, such as ramps, often generate problems of their own. These barriers can affect the life of wheelchair users, impacting on their confidence and causing social isolation. These can be long-term in nature or immediate.
\end{abstract}

\section{Keywords}

accessibility; disability; interdisciplinarity; public transport; science and technology studies; Transport for London; wheelchair

\section{Issue}

This article is part of the issue "Transport Policy and Social Inclusion", edited by Miriam Ricci, Graham Parkhurst and Juliet Jain (University of the West of England, UK).

(C) 2016 by the authors; licensee Cogitatio (Lisbon, Portugal). This article is licensed under a Creative Commons Attribution 4.0 International License (CC BY).

\section{Introduction}

"If I were to ask you to describe transport accessibility for wheelchair users in London as it is today with three words, what are the three words you would choose?"

"Well-intentioned. Inadequate. Uninspiring." (Peter)
With three adjectives, Peter painted a less than ideal image of London's public transport from his perspective. A 25-year-old lawyer who works and lives in Central London, he carefully chose where to live in the European capital to ensure an easier commute, requiring only a short underground journey on the famous Tube network. His is one of several stories and ways of talking about transport and its impact on people's lives, particu- 
larly the influence that transport (in)accessibility might have on wheelchair users' social inclusion. In this article, we want to consider transport and inclusion with wheelchair users' accessibility to the network as the primary focus by using two, quite different, disciplinary approaches-sociology and engineering. The aim is to highlight how both approaches demonstrate, in different ways, how solutions proposed to improve accessibility may also generate future problems for wheelchair users.

In 2005, the main transport authority in London, Transport for London, introduced low-floor buses with boarding ramps for wheelchair users. These buses would eliminate some obvious physical obstacles (compared to the previous model of buses, the Routemaster, which had a step) and permit wheelchair users to board and alight buses, ensuring their inclusion to one mode of the public transport network. However, as we will discuss below, this implementation was not the end of accessibility problems as wheelchair users can also face other issues. Indeed, with wheelchair users being able to physically use the bus, other conflicts began to appear generated by these improvements.

This research was initially developed as a pilot study in 2013 as a collaboration between the UCL departments of Civil, Environmental and Geomatic Engineering and of Science and Technology Studies. The intention was to think about accessibility from both perspectives, quantitative and qualitative, with the aim of seeing whether these two ostensibly incommensurable disciplines could inform each other and provide new insights into transport accessibility for wheelchair users. The aim of this article is to explore the initial results of this interdisciplinary collaboration. To begin, we will briefly describe the policies and regulations which frame transport accessibility in the UK and, more specifically, London. We will then address the question of accessibility with a mixed methods approach, developed below in two separate sections: the first offers a quantitative analysis from an engineering and biomechanics perspective. The second section takes on a qualitative approach, based on the field of Science and Technology Studies. In the last section we ask what new insights were acquired through the collaboration of engineers and social scientists, and discuss the rigidity of the transport system in London as it affects wheelchair passengers.

\section{Background}

Public transport is incredibly important to disabled people in Great Britain. In a recent report analysing secondary data by Jolly, Priestley and Matthews (2006) it was found disabled people attach a greater importance to and almost half are totally reliant on public transport for each journey they take. The main reason for public transport reliance is a lack of access to a car. However, disabled people travel a third less than the general public (Miller, Gillinson, \& Huber, 2006). When public transport is not accessible then mobility can not happen, which in turn can isolate people from the economic, political and social life of the community (Kenyon, Lyons, \& Rafferty, 2002). There are 1.2 million wheelchair users in England (National Health Services Modernisation Agency, 2004). Wheelchair users have specific access needs as most find gaps and steps difficult to overcome, therefore a ramp is needed to overcome the naturally occurring gap between the footway and the bus. Specific to London, guidelines have been developed for accessible bus stop design, and accessible buses (Mayor of London, 2006). A key guideline in this document is the need for a wheelchair accessible space and an interface between the bus and footway which results in a ramp gradient of less that $12 \%$ ( 7 degrees). It is believed this gradient is a compromise between reducing the necessary push force needed to ascend or descend the ramp, and the requirements of the built environment.

Accessibility is a term which means different things to different audiences, generally due to the scale over which it is being measured. At a micro-level accessibility can be measured using the Capability Model (CM), which focuses on measuring the Provided Capabilities of the person when undertaking a task and comparing these to the Required Capabilities of the task (Holloway \& Tyler, 2013). In this respect the CM looks to understand accessibility by understanding the interactions between the person and the environment. Holloway and Tyler explore the $\mathrm{CM}$ with regards to attendant wheelchair propulsion noting that when an assistive technology such as a wheelchair is used by someone this then enhances their provided capability set (for most tasks). In a similar manner the bus ramp can be assumed to reduce the required capabilities thereby increasing accessibility. The CM looks to address how people accomplish these tasks, these 'coping strategies' can range from simply avoiding an activity or adapting the movement required to complete the task. The engineering component in our research uses the Capability Model as its framework to discuss the difficulties wheelchair users have while boarding and alighting a bus. It uses peak and average tangential force when pushing up a standard bus ramp to quantify the provided capability. A model of how a person pushes is developed and the forces occurring at the shoulder are used as a secondary measure of provided capability, while the muscle activity patterns of pushing are used to describe the coping strategies.

On the other hand, accessibility can also be understood from a qualitative perspective as a potential factor for inclusion. Here, we need to listen to people's own experiences of the public transport system to grasp the barriers they face. In our research, the social sciences approach based its framework on the field of Science and Technology Studies, which has built up a substantial body of literature that analyses scientific processes and technological innovation not as 'things in themselves' but as institutions comprised of both things 
and people. As such, any new or changing technology must be considered alongside the variety of users, producers, maintainers, regulators and other groups which come into being or change with the technology itself (Bijker, 1997; MacKenzie \& Wajcman, 1985).

The public transport system lends itself aptly to an STS analysis, particularly given the work of ActorNetwork Theory (ANT) scholars, some of whom have already worked on transport networks (Galis \& Lee, 2014; Latour, 1996). In ANT, a system such as the transport network is perceived as being composed of more than just 'things'. It has its buses, trains, tracks, gears, engines, roads, but it also embraces a much wider variety of actors, from the drivers and staff to the passengers, but also includes diverse groups such as regulators, engineers, mechanics, and others. Moreover, the size of London's public transport system, the placement of its stations, bus stops, the employment of thousands of staff members and the way it transfers millions of passengers, we can see it as a large sociotechnical system with the ultimate goal of carrying its users across the city (Hughes, 1987). A key advantage of viewing the transport system in this way is that it foregrounds the fact that different actors will view the system differently, for instance, a 'perfectly reasonable regulatory standard' from the perspective of managers may be a 'pointless impediment' from the perspective of wheelchair users. Moreover, some of these perspectives may be particularly prominent and visible, whilst others are rendered invisible and marginal (Star, 1991).

STS has also developed some literature which works with disability and disabled people (Blume, 2009; Blume \& Hiddinga, 2010; Winance, 2006), but much of this work is concerned primarily with the development of prostheses and how it interacts with the disabled person (and vice-versa) or with definitions of (dis)ability. Our work, however, will be primarily directed towards thinking about the shaping of the public transport network in London, an example of a sociotechnical system, in which a constellation of human and non-human actors come together to permit passengers to reach their destinations. Additionally, underlying this system there is a history of choices that have been made pertaining to its design and elaboration-choices that impact the users in a variety of ways, both overtly and covertly (Winner, 1980, Woolgar 1991). This observation highlights that the system could be different. Different choices could (and can) be made (Bowker \& Star, 2000; Lampland \& Star, 2009; Star, 1991). Our interviews with wheelchair users sought to re-insert their voices and experiences as active participants within this socio-technical system.

\section{Methods}

During the pilot study, we recruited a number of wheelchair user volunteers to come to the Pedestrian
Accessibility Movement Environment Laboratory (PAMELA) where they would engage in two activities. The first consisted of asking participants to board and alight a bus with the gradient set to 7 degrees. The experiments were recorded using the CCTV cameras onboard the bus and these were analysed to determine the components of the task which caused difficulty. In particular, time to complete tasks, number of pushes and number of attempts were recorded. Having participated in the engineering component of our research, the participants were invited back into the reception of the PAMELA facility. They were then engaged in indepth, semi-structured interviews covering themes around their experience of the London public transport system. These interviews were recorded, transcribed, and then coded using data analysis software according to recurring themes using standard qualitative methods (Silverman 2006; Weber, 1990). Interviewees' names have been anonymised, using pseudonyms of their choice. Unlike quantitative survey techniques, qualitative research does not seek a statistically representative sample but instead seeks to explore, in depth, people's experiences and the meanings they attach to those experiences (Berg, 2001; Seale, 2004).

As our sample sizes for the pilot study were initially small (four participants), the data we are using here has been supplemented for both branches. For the engineering component, we ran an additional study in the PAMELA facility with seven male participants with a history of spinal cord injury. We had initially aimed to have an equal gender split but we struggled to recruit people for the study and failed to recruit any females unfortunately. Each participant used a manual wheelchair as their primary form of mobility. Participants were asked to propel a manual wheelchair on a stretch of level paving, up a $6.5 \%$ incline and up a $12 \%$ incline. On the qualitative side, a series of 18 semi-structured interviews with wheelchair users in London were undertaken in the summer of 2015. This additional data brings the total number of interviews with wheelchair users in this paper to 22 , covering a wide variety of impairments, age, gender, and employment status.

\section{The Engineering/Biomechanics Approach}

\subsection{Pilot Study}

As the numbers were so few in the pilot study, the aim was to understand how people completed the task as opposed to quantifying exactly how difficult it was. The follow-on study which just took a single component of the task-the ramp push-was then conducted to understand exactly how hard the task is. In this instance, wheelchair users were asked to board and alight a bus three times, each time in a way which was easiest for them. For all participants, video was recorded using the standard CCTV cameras on-board a bus (see Figure 1). 
The video data was analysed using video observation software and the GPS clock displayed on the top left corner of each recording. A proxy for provided capability of task time was used to understand how difficult the task of boarding and alighting was for the wheelchair user. Task time was calculated for each trial from this analysis and a description of how each person boards and alights a bus was developed. In addition the coping mechanisms used by people were observed.

There was no difference in alighting time with each person consistently exiting the bus in 4 seconds. However, differences in technique and ability meant that there was a clear difference in boarding time, which is shown in Figure 2. In particular participant MM needed to use the handrails to pull herself onto the bus and $\mathrm{CH}$ failed on two attempts to board the bus on the first time on two of the runs. With regards to coping strategies people adapted their pushing style in different manners. For example in Figure 1 it can be clearly seen that $\mathrm{CH}$ leant forward to maximize the pushing time. However, others used the yellow grab handles or shorter faster pushes to complete the task.

It was apparent by these coping strategies that people were struggling to manage the task. It was decided, following this pilot, to complete a more controlled assessment to compare the amount of force used (provided) to board a bus (a short, steep ramp) with a longer, less steep ramp and also flat footway pushing to understand the potential accessibility barri- er posed by a bus ramp. This was conducted in the detailed biomechanical study.

\subsection{Detailed Biomechanical Study}

The detailed biomechanical study is fully described in Holloway et al. (2015). However, the methods are summarised here to aid the reader. Seven male participants with a history of a Spinal Cord Injury attended PAMELA facility. Each participant used a manual wheelchair as their primary form of mobility. Participants were asked to propel a manual wheelchair on a stretch of level paving, up a $6.5 \%$ incline and up a $12 \%$ incline, which was chosen to replicate the incline found on a London Bus access ramp. During the propulsion tasks, forces applied to the wheelchair push rim to estimate the provided capabilities of the user. In addition upper limb joint movement and shoulder joint muscle activity were recorded and used as inputs to a computer model of the upper limb, to estimate forces experienced at the shoulder joint. Shoulder joint forces have been shown to be correlated to shoulder pain and injury, therefore we think it is essential to understand the forces produced in undertaking the accessibility tasks both in terms of quantifying provided capabilities and also understanding the effect of coping strategies. It should be noted that all participants were free of shoulder pain at the time of this study and had not had a recent shoulder injury or pain.

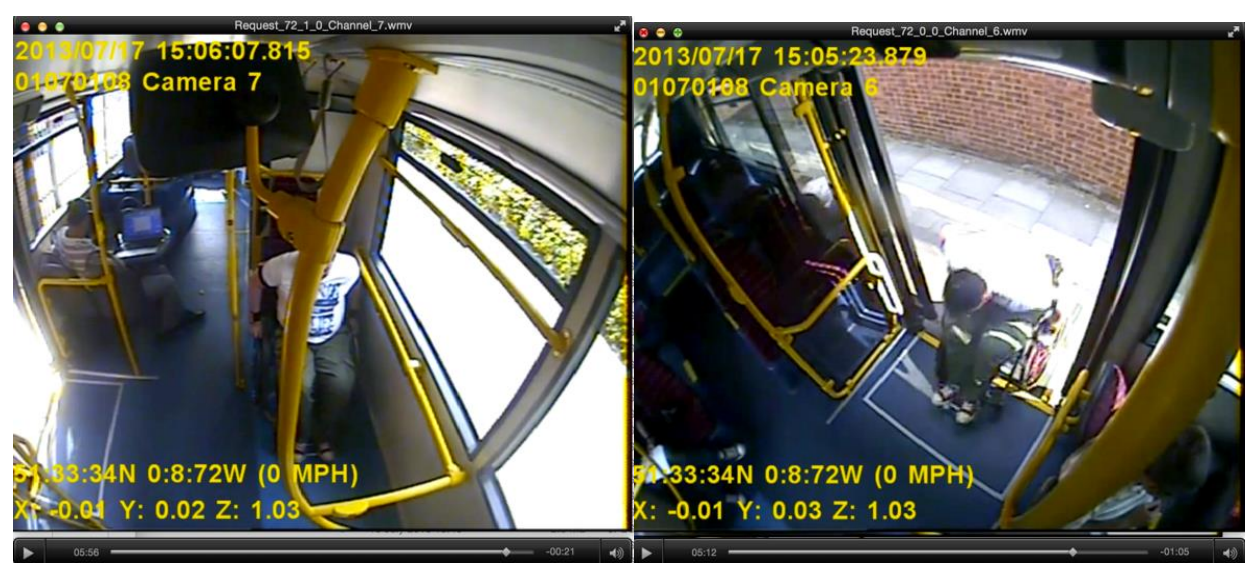

Figure 1. Showing a screen grab of each of the video playback angles used for task time analysis.

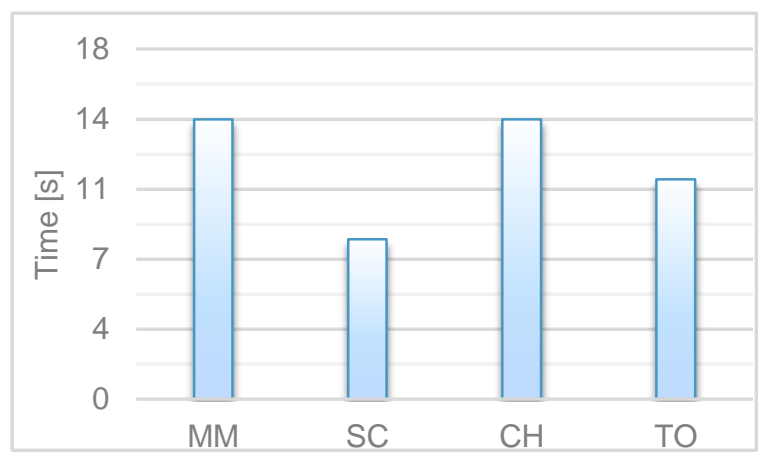

Figure 2. Boarding time (averaged over 3 runs) for each person. 


\subsubsection{Results of Detailed Biomechanical Study}

Provided Capabilities: The total propulsion forces applied to the wheelchair push rim were significantly affected by the tasks. Climbing the $6.5 \%$ incline people used significantly greater force than level propulsion $(106.90 \mathrm{~N}$ vs. $50.36 \mathrm{~N})$, and climbing the $12 \%$ incline people used a significantly greater force than climbing the $6.5 \%$ incline $(139.63 \mathrm{~N}$ vs. $106.90 \mathrm{~N})$. These forces translated into significant increases in shoulder joint forces experienced during the incline propulsion tasks. During level propulsion, peak shoulder joint forces were under one body weight. During the $6.5 \%$ incline, peak shoulder forces were over two times body weight and during the $12 \%$ incline task, peak shoulder forces were over three times body weight.

Coping strategies: How each individual managed to generate the push force varied and this is reflected in the different muscle activity. Generally there were significant increases in peak muscle activity levels during the incline tasks compared to level propulsion. During level propulsion, peak muscle activity levels around the shoulder joint were on average $26 \%$ of maximum. When climbing the $6.5 \%$ incline, peak muscle activity levels were on average $63 \%$ of maximum and when climbing the $12 \%$ incline, peak muscle activity levels were on average $77 \%$ of maximum. Interestingly it would appear that when going up a $6.5 \%$ slope the deltoid, which is the very large muscle at the top of arm reaches a maximum, and as the person attempts to go up a $12 \%$ slope they are forced to increase the amount of muscle activity in smaller muscles such as the infraspinatus.

\section{The Social Science Approach}

\subsection{Findings}

During the interviews, we spoke to wheelchair users about the barriers that they face and the impact that this has on their daily life. Through the 21 conversations, we attempted to understand the origins of problems these users might face and whether we could attempt a classification of these barriers. Through coding the interviews, we generated three heuristic categories of problems narrated by the interviewees as distinct moments and barriers: spatial, technical, and social. Here, we would like to reinforce that these classifications are actor's categories. For example, while accounting their experiences, our interviewees would narrate the barriers as distinct moments, e.g. "One day, I had a problem because of the ramp. Another day, I had a problem because of the lack of space."

\subsubsection{Technological Barriers}

"I've been to so many bus depots because the ramps were broken and I can't get off. You end up going to a depot." (Adam)

"I accept that it's improved and improvements that have been made have been amazing in some respects, but on the other hand, it's still as if.... It's still as stressful if not more stressful because the wonder of technology is the wonder that it ever works." (Michael)

In order for the space on the bus to even become an issue as a passenger, a wheelchair user must first be able to board it at all. Transport for London prides itself in its fleet of low-floor buses, all of which have mechanical ramps to be deployed for a wheelchair user to be able to board and alight. This change in the rolling stock of London buses in $\mathbf{2 0 0 5}$ was a true turning point for accessibility throughout the city. It is, of course, dependent on this technological artefact functioning as intended: a broken ramp, which might break either before or after the wheelchair has boarded the bus, can mean a passenger having to wait hours or take a long detour. What emerged in our interviews is a sense of the wide variety of ways things could go wrong on buses and throughout the transport system.

Wheelchair users are dependent on boarding ramps when it comes to the London Overground and Underground train stations that are accessible from streetlevel to the platforms. Here, however, it is not just an issue of the ramp working. These are low-tech versions of the fitted, mechanical ramps on buses and are dependent on others deploying them correctly:

"The chap with the ramps did arrive and he went to put the ramp for me get off with the doors open. The driver of the train either hadn't seen him or didn't want to see him because they were running behind schedule, or whatever, so the doors shut with the ramps in a half position, me inside, and actually clunked the chap on the platform so he fell over." (Basil)

It becomes particularly interesting to think about the ramp as a potentially problematic factor in accessibility for wheelchair users when we think back to the research done by engineers. Despite none of our interviewees having mentioned developing joint pain as a result of ramp inclination, this is still a problem which engineers have pointed out. In addition, some wheelchair users have mentioned the steepness of ramps as a problematic factor in accessibility as it makes their boarding of the bus more difficult, and their alighting more dangerous.

There is a variety of technological 'bits and bobs' which also frustrate and hinder wheelchair users beyond the practicality of the ramps, both manual and electric. For instance, inside the buses, a special button by the wheelchair priority area is supposed to be used to alert the driver that they would like to get off at the 
next stop. This allows the drivers to get ready to deploy the ramp, and makes a sharp siren noise to get their attention. The siren noise is also activated continuously while the ramps are being put out and coming back in, perhaps to alert other passengers and passers-by on the street of what is happening. Interviewees such as Alex and Sophie have expressed some discomfort at this because it calls attention to them, and even expressed the experience as akin to public humiliation:

"[Imitates alarm noise] And everyone looks, everyone stares, and I'm like, yeah, I'm just getting on the bus." (Alex)

"So I don't like the fact that there's the siren that starts wailing at you, or at everybody, when you're about to get on or about to get off the bus. It's all a bit of a big faff, but you get used to it. I mean, public humiliation seems to be...you've got to be able to deal with it if you're disabled anyway, because people will look at you, people will...etc." (Sophie)

Despite such barriers not affecting the physical acts of boarding and disembarking, they impact on wheelchair users' wellbeing, their impressions of the public transport system and, in the above quote, compound Sophie's existing sense of being stigmatised. These negative experiences play into their personal perceptions but also on their desire to use the network and overcome potentially being confined to their home and to engage in activities beyond their local community.

\subsubsection{Spatial Barriers}

"You're in a chair and you can't move and you can't get out of the space so they tend to close up around you." (C.S.)

"You'll hear this time and time again, there's generally only one wheelchair space, but it's also the space that can be used for toddlers, buggies, suitcases, and things like this." (Basil) "And also sometimes you know, they have rails that are probably in the way of the user to manoeuvre within the space." (Um Hayaa)

Space is an inevitable part of the background whenever people speak in general about transport: moving around the city; going from Northeast to Southwest; or the mileage from one stop to another (Vertesi, 2008). For wheelchair users, another kind of space was present in our interviews: personal or manoeuvrable space. In the above quotes, the 'space' referred to is the 'wheelchair priority area', a demarcated location on the bus which is specifically designated for these passengers' use. It is prescribed as "the only place wheelchair users can travel safely" (Transport for London, 2014, p. 70) and these passengers are required to place themselves facing opposite to the direction of travel.
Despite the title of 'wheelchair priority space', interviewees reported that it is often a key source of anxiety before travelling. The issues around it are many, from the size of their own wheelchairs and difficulty manoeuvring in or out of the space, to the sadness of not being able to travel with a friend who is also a wheelchair user, or even the much publicised debate around buggy and pushchair users or luggage sharing the space (Bellisario, 2012; Moss, 2013). The direction of travel can also provide a degree of frustration and discomfort. In these cases, the users described how they subvert the wheelchair space by travelling in a way that suits them best:

"For me, I prefer to go face-in and hold on to the rails, I find that fine. The reverse side, I sometimes get that sick feeling." (M.)

"I suffer sometimes with travel sickness and so I find it easier sometimes to sit the opposite way to how you're supposed to sit in the wheelchair space." (Michael)

Despite this subversion of the space, this can also be the source of anxiety, as both interviewees laughed nervously and mentioned they probably should not be saying that. They expressed that some bus drivers understand, but that it is often a risk in terms of their, and other passengers', safety. Interestingly, here we find another example of a potential solution to wheelchair users' travelling needs which is also proving to be more complicated than initially intended. Like the ramp, the wheelchair priority area was meant to facilitate accessibility but is also a source of anxiety.

\subsubsection{Social barriers}

"Obviously, you've heard about the problems with wheelchairs vs. buggies on that space. That's not the only problem that you'll actually find. You'll find that you've got people standing in the space who don't necessarily want to move, or you've got people who've got luggage in the space who don't want to move, or you've got older people who've got their shopping trolley in the space. That's always very problematic." (Marie)

"It is like a battle of wheels, buggy versus wheelchair. It should never, never be that way. It should never be that way." (Faith)

The category of social barriers - by which we specifically mean barriers created by other people-was particularly evident when interviewees discussed what has perhaps been the most prominent debate in the UK media around transport accessibility, the "wheelchair vs. buggies" priority debate. In 2012, Doug Paulley sued FirstGroup in Yorkshire after having been denied access to a bus because the space was occupied by a 
mother with a pushchair (Press Association, 2014). Three years and one overruling later, the case has escalated and will be heard by the Supreme Court in the UK. It was previously established that the wheelchair area should be used on a first-come, first-served basis but for the wheelchair users we interviewed this can sound outrageous when they are only given one space to ride on the bus.

"A buggy can fold, they have that option." (M.)

"And when I see things like that, my reaction is, it's not about who's more important, it's about who has a choice; so I do not have a choice about my use of the wheelchair whereas a baby can be got out of its buggy." (Diana)

After research done in 2012, Transport for London launched a campaign that November to address the issue, with campaign posters on buses and at bus stops in bold black and red letters asking, "Buggy users, please make way for wheelchair users". Interviewees' perceptions on the impact of that campaign were mixed, but conflicts with bus drivers were also mentioned as a source of anxiety. In some cases, they reported, drivers are unclear on the rules of whether a wheelchair user and a buggy are allowed to share the space, or in some cases drivers simply do not stop the bus at all for a wheelchair user to board it.

"I've had buses drive past me without even stopping, you know, and I've been sent to the end of the route occasionally because they've forgotten I'm actually on the bus." (Michael)

Yet these conflicts with buggy users and drivers are not the only social barriers for wheelchair users. A large number of interviewees expressed concern at social attitudes towards disabled people in London. Negative reactions towards them take a variety of forms such as awkward "nosy questions", invading their personal space by pushing their wheelchair without asking, or even outright verbal and physical abuse. Participants described these social issues as a mix of a lack of public awareness around disability and, according to some interviewees, a media push towards depicting disabled people as "scroungers". To some, this stigmatisation is being done with the government's support:

"I think we've only got the rights that we fought for and it takes constant ambition to add onto these fights because in the interest of saving money our government has, I believe, quite deliberately and callously waged a media campaign depicting us as a drain on the state and an unacceptable one at that." (Leda)

Although our focus in this article is on barriers, it is im- portant to add that these negative views were also matched by comments from the interviewees that there was a willingness to help. Moreover, in three interviews the wheelchair users explicitly stated that they had no issues with buggies at all.

\subsubsection{Isolation}

These three different sources of barriers to using the public transport system create a sense of anxiety and frustration in the wheelchair users we interviewed, but perhaps more problematic is the social consequence of this fear. For instance, when asked what happens when a trip goes wrong and they are faced with a barrier, Marie described how all you can do is complain to the transport authority and, in response, receive a generic email. She explained that this "puts you off" travelling:

"It isolates you even more because your world is getting smaller, and smaller, and smaller, all the time...." (Marie)

A functioning, accessible, transport system, particularly in a city as large and crowded as London, is the difference between being able to get around, and isolation. Options to public transport would include taxis or personal cars, which are described as "luxury" items but also, in some cases, as the only viable option.

"If I use an adapted vehicle, it's much better, much easier, than being pressured to wait in the cold at the bus stop hoping that the first bus will accommodate my needs." (Um Hayaa)

Um Hayaa had to resort to private transport to pick up her daughter from a variety of after school activities, otherwise she would have had to take three different buses, each trip fraught with the anxiety of broken ramps, impatient drivers, and not enough space. However, she had to make an investment choice to purchase a vehicle, one which not all wheelchair users are able to make. Sophie, who also makes use of a private vehicle, described how aware she is that it is a privilege not to worry about public transport. Beyond the costs of a private car, wheelchair users often have to worry about the costs related to their mobility aid itself. She explains:

"Disability is a luxury that not many people can afford, and that's the problem. People don't realise how expensive everything gets. Either how isolated life is if you don't have the money and/or the equipment, which, equipment means money. And that's why people are so scared of disability." (Sophie)

The general narrative around the public transport net- 
work in London for wheelchair users that emerged in our interviews centres on anxiety, pre-planning, battles, and effort. The consequence of these impediments, it is suggested, is greater isolation for these groups. In the words of one of our interviewees:

"I'm sure you know, getting out and about changes people's lives, and it makes things.... Being social makes you much more alive, much healthier, and public transport is really good for that if you've got that option[.]" (Alan)

\section{Discussion}

\subsection{Well-Meaning Solutions}

When Transport for London writes about accessibility in its network, many figures are cited, from its bus fleet being $98 \%$ low floor access (the few exceptions being some older Routemaster models still used on Heritage routes) to a quarter of the Tube stations and half of the Overground stations having step-free access. All of these figures are to be welcomed. The image of this network is quite positive, and wheelchair users do seem to benefit extraordinarily. But this should not allow us to ignore that the reality of the network does not always match these numbers, and wheelchair users still face the variety of barriers described above.

In addition to the barriers wheelchair users themselves describe as facing, the engineering section of our research has found that with each push the make, they further wear their shoulder and eventually, nearly all will have upper limb injuries, some so severe they will be unable to independently push themselves. A number of factors effect the development of injuries and the associated pain. These include: the cyclical nature of the wheelchair push cycle (Kotajarvi et al., 2004; Mercer et al., 2006), the low gross mechanical efficiency of wheelchair pushing-only $10 \%$ of effort goes directly into making a person move forwards (De Groot, Veeger, Hollander, \& van der Woude, 2002) and challenging surfaces (Holloway et al., 2012). To give an indication of the scale of the problem, the incidence of shoulder pain is reported to range from 42\% (Dalyan, Cardenas, \& Gerard, 1999) to 66\% (Fullerton, Borckardt, \& Alfano, 2003), with the most commonly reported injury damage to the rotator cuff muscles (Akbar et al., 2010).

It was found that upper limb demand and injury risk were significantly greater during incline wheelchair propulsion in comparison to level propulsion, which means that ramps at a greater incline for boarding and alighting buses and trains can further add to the risk. As the gradient of the incline increased, upper limb demand and injury risk increased. During level propulsion, on average, muscles around the shoulder were working at $27 \%$ of their maximum and joint forces were less than one body weight. During the $12 \%$ incline task, on average, muscles around the shoulder were working at $77 \%$ of their maximum, and joint forces were above three times body weight. The results demonstrate that a common daily task such as accessing a bus places a high demand on the upper limbs of a manual wheelchair user. Push force is an important factor in assessing the accessibility of transport for wheelchair users as it has been shown to be directly proportional to forces which occur at the shoulder. The shoulder is the most commonly injured joint for wheelchair users with injury rates ranging from $42 \%$ (Dalyan, Cardenas, \& Gerard, 1999) to 66\% (Fullerton et al, 2003). Shoulder pain can be so severe that it leaves the person without an independent form of mobility. It has been noted previously that the method of assessment of accessibility can affect the resulting guidance, and that even when guidance is followed it can be challenging to wheelchair users (Holloway \& Tyler, 2013). Guidance such as Manual for Streets 2 (Department for Transport, 2007) used by the UK to help produce accessible pedestrian infrastructure are not always produced based on empirical evidence, and are often developed via case studies or rule of thumb practice which. In a society where sensing technology is becoming ubiquitous, there is an opportunity to both collect more diverse and also dynamic datasets and to use these to assess infrastructure policy changes. Projects such as Wheelmap (www.wheelmap.org) and Accessible Routes form Crowd-sourced Cloud Services (www.arccs.org) are beginning to develop web and mobile tools to enable more dynamic modelling of accessibility. The challenge will be to understand how such crowd-sourced data can be used effectively to inform and evaluate policy, and indeed to see if it can be shared across traditional policy sectors e.g. health (rehabilitation) and transport (accessibility).

This data from the engineering component of our research is enlightening when paired with the narratives put forward by the wheelchair users themselves. As pointed out in section 5.2.1., though our interviewees did not specifically indicate developing an injury as a particular hinderance in their use of the public transport system, ramps did figure prominently as a potential barrier. Yet it seems ironic that the enabler of their access to public transport can also be a problematic factor. The same thing can be seen with the other aspects of 'accessibility': the alarms which signal ramp deployment are seen as unwanted attention, the wheelchair priority areas become contested spaces with pushchairs and luggage, etc. What our interdisciplinary collaboration has helped highlight is this paradox where well-meaning solutions do not simply solve the problems with accessibility. The engineering approach has shown this through ramp inclination when even where guidance is followed, injuries can still occur, while the sociological perspective has teased this 
out from wheelchair users' description of the barriers they face. We would like to make it clear that we are not criticising the improvements that have been made as such, but rather that they should be taken as a lesson where, rather than thinking in terms of solutions as an end-point we should speak of ongoing conversations and of adjustments to the network. However, this becomes difficult if the public transport system is seen as a stabilised network.

\subsection{Standardisation and Rigidity}

It would come as no surprise to STS scholars that, despite the heuristic classification of the different barriers made by our interviewees into social, spatial, and technical origins, the problem is not always so clearcut. Indeed, most STS scholars make the point that these classifications are rarely, if ever, obvious (Bowker \& Star, 2000). In other words, despite the problem seeming to be due to a technical issue, it can also be related to spatial and social dimensions. Broken or faulty ramps are a good example of this blurring of categories. This technology was developed with sensors which withdraw if an obstacle is detected. If the ramp does not deploy appropriately when an obstacle is detected, is the barrier for the wheelchair user spatial or technological? The ramp does not work (technical) but is this because of spatial features such as the presence of street furniture, or the design of the curbs (either too low or too high)? Similarly, the debate around the wheelchair priority area can lend itself to a similar question: is the problem social (negotiating priority with other passengers on the bus) or is it spatial (the space is not big enough)?

The difficulty in drawing these lines is testament to how tightly knitted these different aspects of the network are, which brings us back to the notion of sociotechnical systems referred to in the background section above. In a system where there are numerous types of agents, human and non-human, physical and non-tangible (such as legislation), intense collaboration between all of them is imperative to make it a cohesive whole. Yet this very cohesiveness is dependent on another process, that of standardisation and consolidation. Hughes describes consolidation as the moment in the life of a sociotechnical system in which there are few competing systems (Hughes, 1987). Transport in London has definitely reached such a period in its development as it is controlled by a single higher authority, Transport for London. Historically, much work goes into reaching this moment of consolidation, mainly by passing through the development of standards, which function as a unifying language, to ensure that all different actors and agents of the system are communicating and compatible (Bowker \& Star, 2000; Lampland \& Star, 2009; Scott, 1998; Timmermans \& Berg, 1997). Generally, this has been a successful process for most users of the London transport system, so why are experiences so irregular for wheelchair users?

Given the age of various means of transport in London, we can say that the process of standardisation and stabilisation have been ongoing for at least a century. The London Underground celebrated its 150-year anniversary in 2013. These processes happened throughout a period where the perception of disability and impairment were different. Disability Studies scholars argue that through the Victorian era and up until the 1960s, there was a medical model of disability which individualised impairments and placed the burden of care on the disabled person and/or their family. This model normalised the absence of disabled people from social settings, giving the idea that it was a person's impairment which hindered their inclusion into society. In the 1960s, the social model of disability made its first appearances with a series of disabled rights activist groups arguing that disability has its origins in social notions (Blume \& Hiddinga, 2010; Davis, 1999; Linton, 1998; Shakespeare, 2006). The Union of the Physically Impaired Against Segregation defined disability as "the disadvantage or restriction of activity caused by a contemporary social organisation which takes no or little account of people who have physical impairments and thus excludes them from participation in the mainstream of social activities" (Union of the Physically Impaired Against Segregation, 1976).

It is only in the past two decades that accessibility has been added to the transport agenda in the UK, with the backing of legislation such as the Disability Discrimination Act of 1995, now superseded by the Equality Act 2010. Much of the negative experiences related by wheelchair users are arguably due to an initial lack of inscription of their needs into the transport network, which up until the past decades did not consider them as potential passengers, as well as a slow shift of social perceptions and assumptions about disabled people in general (Beckett \& Campbell, 2015; Shakespeare \& Watson, 1997). As Star argues: “A stabilised network is only stable for some, and that is for those who are members of the community of practice who form/use/maintain it" (Star, 1991, p. 42). For the moment, wheelchair users are still somewhat 'nonstandard 'agents within this sociotechnical system and do not (yet) experience a stabilised network.

We argue that, perhaps precisely because wheelchair users are non-standard agents, they experience the transport system through its fragments rather than its entirety. For this reason, the narratives given by interviewees often point to different and diverse factors (space, people, technology) rather than the system as a whole (as ANT scholars tend to do). The use of standards as necessary to regulate and stabilise the system is what is now locking out these users from experiencing it as such. This is reminiscent of what Scott (1998) described in Seeing Like a State, where the establishment 
of norms and regulations from a top-down approach does not necessarily translate in a positive and productive manner for those on the ground, such as the development of accessibility regulation still straining the bodies of wheelchair users and causing harm, as is shown by our engineering section. This feeds back to what was discussed in section 6.1. on prescribing solutions as an end-all, when for the many actors who interact with these proposals they may generate problems in and of themselves.

We would also like to briefly point out that it is important to remember that wheelchair users are not 'passive'. While these barriers strain their journey through the system, they also develop their own tactics for dealing with these issues. Our interviewees have provided some examples, such as $M$. in a quote above mentioning that she gets into the space facing forwards and holding onto the rails. Other examples from out interviews include wheelchair users carrying toolkits to fix ramps, 'bunny-hopping' off a bus or train, using their wheelchairs on escalators, or even organising activists group to campaign for improved accessibility. This is a rich area of research that merits further exploration in the future as it can provide some insight and suggestions for improvement in transport policy.

\section{Conclusion}

In this article we intended to think about accessibility through an interdisciplinary lens, using both an engineering and a sociological approach, and consider the new insights this collaboration might bring. Transport is an essential service to the population which ensures people's inclusion in society as it provides the link between the private (the home) and the public (the museum, coffee shop, Parliament, etc.) spheres. In the case of our participants, we can see that issues around the accessibility of public transport can lead to anxiety and social isolation, but also to physical injury. The collaboration between disciplines helped to highlight that what can be framed as a solution to barriers in accessibility can also generate problems in itself, such as ramps becoming broken or straining wheelchair users' bodies and causing harm. This is often due to the 'addon' nature of some of these fixes onto a system that has already been mostly stabilised in the past century. Despite STS and ANT theories telling us that these systems are more complicated, our interviewees described the issues they face as physical, spatial, or social which we suggest is due to their experiences being fragmented.

For this reason, policy-making in transport, including the establishment of legislation, regulations and best-practice guides, should be developed in as plural a manner as possible where, rather than speaking in terms of 'solutions', ongoing conversations about improvements are held. The physical and spatial envi- ronment needs to be understood and people's abilities can be measured to provide better guidance. This should also be supplemented by the understanding that transport is an extremely large network which encompasses not only things, technologies and policies, but also a wide variety of people and social interactions. A plural approach to investigating the limits and weak points of public transport networks, including engineering, biomechanics, sociology, city planning, among others, can permit a wider range of solutions to be proposed.

\section{Acknowledgments}

All authors thank the numerous participants in our research. The first author also thanks the Brazilian CAPES Foundation for the funding of her doctoral research.

\section{Conflict of Interests}

The authors declare no conflict of interests.

\section{References}

Akbar, M., Balean, G., Brunner, M., Seyler, T. M., Bruckner, T., Munzinger ... Loew, M. (2010). Prevalence of rotator cuff tear in paraplegic patients compared with controls. J Bone Joint Surg Am, 92(1), 23-30.

Beckett, A. E., \& Campbell, T. (2015). The social model of disability as an oppositional device. Disability \& Society, 30(2), 270-283.

Bellisario, R. (2012, July 10). Refused access: Fighting for the right to travel on the buses. The Guardian. Retrieved from http://www.theguardian.com/society/ 2012/jul/10/fighting-right-travel-buses

Berg, B. L. (2001). Qualitative research methods for the social sciences. Boston, MA: Allyn and Bacon.

Bijker, W. E. (1997). Of bicycles, bakelites and bulbs: Toward a theory of sociotechnical change. Cambridge, MA: The MIT Press.

Blume, S. (2009). The artificial ear: Cochlear implants and the culture of deafness. Rutgers University Press.

Blume, S., \& Hiddinga, A. (2010). Disability Studies as an academic field: reflections on its development. Medische Antropologie, 22(2), 225-236.

Bowker, G. C., \& Star, S. L. (2000). Sorting things out: Classification and its consequences. Cambridge, MA: The MIT Press.

Dalyan, M., Cardenas, D. D., \& Gerard, B. (1999). Upper extremity pain after spinal cord injury. Spinal Cord, 37(3), 191-195.

Davis, L. J. (1999). Crips strike back: The rise of disability studies. American Literary History, 11(3), 500-512.

De Groot, S., Veeger, H. E. J., Hollander, A.P. \& van der Woude, L. H. V. (2002). Consequence of feedbackbased learning of an effective hand rim wheelchair force production on mechanical efficiency. Clinical 
Biomechanics, 17(3), 219-226.

Department for Transport. (2007). Manual for Streets. London, UK: Thomas Telford Publishing. Retrieved from http://www.dft.gov.uk/pgr/sustainable/manfor streets

Fullerton, H. D., Borckardt, J. J., \& Alfano, A. P. (2003). Shoulder pain: A comparison of wheelchair athletes and nonathletic wheelchair users. Medicine \& Science in Sports \& Exercise, 35(12), 1958-1961.

Galis, V., \& Lee, F. (2014). A Sociology of treason: The construction of weakness. Science, Technology \& Human Values, 39(1), 154-179.

Holloway, C. (2011). The effect of footway crossfall gradient on wheelchair accessibility (Doctoral dissertation). University College London, London.

Holloway, C., Richards, R., Smitham, P., Gall, A. \& Tyler, N. (2012) The effect of everyday outdoor tasks on wheelchair propulsion patterns: results linking EMG analysis and a new lightweight force sensing wheel. In (Proceedings) 51st Annual Scientific Meeting of the International Spinal Cord Society, London, 2012.

Holloway, C., \& Tyler, N. (2013). A micro-level approach to measuring the accessibility of footways for wheelchair users using the capability model. Transportation Planning and Technology, 36(7), 636-649.

Holloway, C. S., Symonds, A., Suzuki, T., Gall, A., Smitham, P., \& Taylor, S. (2015). Linking wheelchair kinetics to glenohumeral joint demand during everyday accessibility activities. In 2015 37th Annual International Conference of the IEEE Engineering in Medicine and Biology Society (EMBC) (pp. 2478-2481). http://doi.org/10.1109/EMBC.2015.7318896

Hughes, T. P. (1987). The evolution of large technological systems. In W. E. Bijker, T. P. Hughes, \& T. J. Pinch (Eds.), The social construction of technological systems: New directions in the sociology and history of technology (pp. 51-82). Cambridge, MA: The MIT Press.

Jolly, D., Priestley, M. \& Matthews, B. (2006). Secondary analysis of existing data on disabled people's use and experiences of public transport in Great Britain. University of Leeds, UK: Disability Rights Commission.

Kenyon, S., Lyons, G., \& Rafferty, J. (2002). Transport and social exclusion: Investigating the possibility of promoting inclusion through virtual mobility. Journal of Transport Geography, 10(3), 207-219.

Kotajarvi, B. R., Sabick, M. B., An, K. N., Zhao, K. D., Kaufman, K. R., \& Basford, J. R. (2004). The effect of seat position on wheelchair propulsion biomechanics. J Rehabil Res Dev., 41(3B), 403-14.

Lampland, M., \& Star, S. L. (2009). Standards and their stories: How quantifying, classifying, and formalizing practices shape everyday life. Ithaca, USA: Cornell University Press.

Latour, B. (1996). Aramis, or, the love of technology. Cambridge, MA: Harvard University Press.

Linton, S. (1998). Disability studies/not disability studies.
Disability \& Society, 13(4), 525-539.

MacKenzie, D. A., \& Wajcman, J. (1985). The social shaping of technology: How the refrigerator got its hum. Milton Keynes, UK: Open University Press.

Mayor of London. (2006). Accessible bus stop design guidance. Transport for London. Retrieved from http://content.tfl.gov.uk/accessibile-bus-stop-design -guidance.pdf

Mercer, J. L., Boninger, M., Koontz, A., Ren, D., DysonHudson, T., \& Cooper, R. (2006). Shoulder joint kinetics and pathology in manual wheelchair users. Clinical Biomechanics, 21(8), 781-789.

Miller, P., Gillinson, S., \& Huber, J. (2006). Disablist Britain: Barriers to independent living for disabled people in 2006: Scope.

Moss, A. (2013, November 1). Wheelchair users' fight for bus space. BBC. Retrieved from http://www.bbc.co. uk/news/uk-england-24614134

National Health Services Modernisation Agency. (2004). Improving services for wheelchair users and carersGood practice guide. London: Department of Health. Retrieved from http://www.dh.gov.uk/en/Publicatio nsandstatistics/Publications/Publications PolicyAndG uidance/DH_4103389

Press Association. (2014, November 21). Disabled man forced off bus by refusal to move pram sparks equality test case. The Guardian. Retrieved from http:// www.theguardian.com/society/2014/nov/11/disable d-man-forced-off-bus-refusal-move-pram-sparks-equ ality-test-case

Scott, J. C. (1998). Seeing like a state: How certain schemes to improve the human condition have failed. London: Yale University Press.

Seale, C. (2004). Social research methods: A reader. London: Routledge.

Shakespeare, T. (2006). The social model of disability. The disability studies reader, 2, 197-204.

Shakespeare, T., \& Watson, N. (1997). Defending the social model. Disability \& Society, 12(2), 293-300.

Silverman, D. (2006). Interpreting qualitative data: Methods for analyzing talk, text and interaction. London: SAGE.

Star, S. L. (1991). Power, technology and the phenomenology of conventions: On being allergic to onions. In J. Law (Ed.), A sociology of monsters: Essays on power, technology and domination (pp. 26-56). London: Routledge.

Transport for London. (2014). Big red book. London: Transport for London.

Timmermans, S., \& Berg, M. (1997). Standardization in action: Achieving local universality through medical protocols. Social Studies of Science, 27(2), 273-305. doi:10.2307/285471

Union of the Physically Impaired Against Segregation. (1976). Fundamental principles of disability. In M. Oliver (Ed.), Understanding Disability: From Theory to Practice (pp.19-29). Basingstoke, UK: Palgrave Mac- 
millan.

Vertesi, J. (2008). Mind the gap: The London underground map and users' representations of urban space. Social Studies of Science, 38(1), 7-33.

Weber, R. P. (1990). Basic content analysis. Newbury Park, CA: SAGE.

Winner, L. (1980). Do artifacts have politics? Daedalus, 109(1), 121-136.
Winance, M. (2006). Trying out the wheelchair: The mutual shaping of people and devices through adjustment. Science, Technology \& Human Values, 31(1), 52-72.

Woolgar, S. (1991). Configuring the user: the case of usability trials. In J. Law (Ed.), A sociology of monsters: Essays on power, technology and domination (pp. 6675). London: Routledge.

\section{About the Authors}

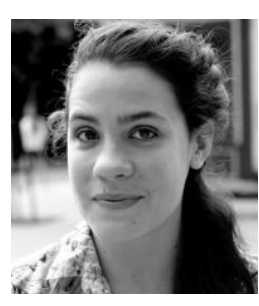

Raquel Velho is a doctoral candidate in the Department of Science and Technology Studies, University College London where her research investigates the resistance-practices wheelchair users develop while using the public transport system in London in order to tackle a diversity of barriers in their journey. She obtained her Master's degree in Science, Technology, Medicine and Society from Imperial College London and is interested in the intersection of sociology of technology and disability studies.

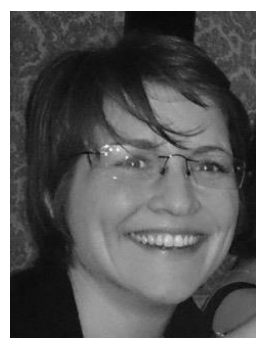

Catherine Holloway is a senior lecturer at University College London's Interaction Centre where she researches how to better design assistive technologies and accessibility more widely. Catherine is the Director of the Biomedical Instrumentation Group at UCL's PAMELA facility and the CEO of Movement Metrics, a social enterprise to develop sensors and metrics to measure activity of persons with disabilities.

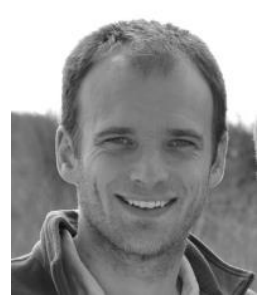

Andrew Symonds received his BSc in Physiotherapy in 2004 from Kings College London and his MRes in Healthcare Engineering for an Ageing Population from University College London in 2013. He is currently working as a PhD student at the University College London Aspire Centre for Rehabilitation Engineering and Assistive Technology. His PhD work is focused on the biomechanical analysis of over ground manual wheelchair propulsion.

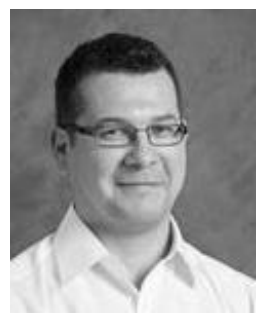

Brian Balmer is Professor of Science Policy Studies, Department of Science and Technology Studies, University College London where his research combines historical and sociological approaches to understanding the nature of expertise, particularly in relation to the life and biomedical sciences. He has published widely on the role of volunteers in biomedical research, military technology and society, and biotechnology policy. 